\title{
The Charles Perkins Centre's Twins Research Node
}

\author{
Lucas C. Ferreira, ${ }^{1}$ Jeffrey M. Craig, ${ }^{2,3}$ John L. Hopper, ${ }^{1}$ and Susan E. Carrick ${ }^{4}$ \\ ${ }^{1}$ Centre for Epidemiology and Biostatistics, Melbourne School of Population and Global Health, University of Melbourne, \\ Melbourne, Victoria, Australia \\ ${ }^{2}$ Murdoch Children's Research Institute, Melbourne, Victoria, Australia \\ ${ }^{3}$ Department of Paediatrics, University of Melbourne, Melbourne, Victoria, Australia \\ ${ }^{4}$ The Charles Perkins Centre's Twin Research Node, The University of Sydney, Sydney, New South Wales, Australia
}

\begin{abstract}
Twins can help researchers disentangle the roles of genes from those of the environment on human traits, health, and diseases. To realize this potential, the Australian Twin Registry (ATR), University of Melbourne, and the Charles Perkins Centre (CPC), University of Sydney, established a collaboration to form the Twins Research Node, a highly interconnected research facility dedicated specifically to research involving twins. This collaboration aims to foster the adoption of twin designs as important tools for research in a range of health-related domains. The CPC hosted their Twins Research Node's launch seminar entitled 'Double the power of your research with twin studies', in which experienced twin researchers described how twin studies are supporting scientific discoveries and careers. The launch also featured twin pairs who have actively participated in research through the ATR. Researchers at the CPC were surveyed before the event to gauge their level of understanding and interest in utilizing twin research. This article describes the new Twins Research Node, discusses the survey's main results and reports on the launch seminar.
\end{abstract}

Keywords: twin research, collaboration, epidemiology, epigenetics, twins

The Charles Perkins Centre (CPC) is dedicated to finding innovative research and teaching solutions focused on easing the global burden of obesity, diabetes, cardiovascular disease, and related conditions. Its systematic approach connects health scientists, researchers, and clinicians with a wide array of stakeholders. The CPC's research domains and themes are addressed by a richly linked network of more than 60 project nodes coming together across disciplines to collaboratively address major knowledge gaps.

The Australian Twin Registry (ATR) conducts and facilitates medical and scientific studies involving twins, with the aim of realizing the full potential of twin research to improve the health and wellbeing of all Australians. It maintains a national register of twin pairs, multiples and their relatives who are willing to consider participation in health-related research, while fostering the adoption of twin research designs and their inclusion into health researchers' repertoire to help address relevant questions of interest.

The CPC and the ATR have developed a partnership to encourage the growth and development of twin research within the CPC's research community, and to facilitate opportunities and build new collaborations through the creation of the CPC's Twin Research Node. To achieve such objectives, the CPC's Twin Research Node will support the training and development of Australian and international researchers in the methodology and practice of studies in- volving twins, assist researchers to design, conduct and analyze twin studies, and support and supervise $\mathrm{PhD}$ scholarships for work related to twin research. It will become highly interconnected and cross-disciplined to support researchers at the CPC in their pursuit for new perspectives and scientific paradigm shifts, while also welcoming collaborative efforts from all parts of the world.

\section{The Twins Research Node Launch}

The University of Sydney's CPC hosted the Twin Research Node launch in collaboration with the ATR on October 30, 2015. Recent findings in twin research were presented, along with brief explanations of how different twin designs can be used for different applications. As happened before at the 'Healthier Kids: Insights from Twin Research' conference (Segal, 2015) twin pairs were also invited to be part of an informal on-stage discussion about their involvement and expectations in research.

RECEIVED 15 April 2016; ACCEPTED 28 April 2016. First published online 15 June 2016.

ADDRESS FOR CORRESPONDENCE: Susan E. Carrick, D17, The Hub, The Charles Perkins Centre, John Hopkins Drive, The University Of Sydney, Sydney 2006, Australia. E-mail: susan.carrick@sydney.edu.au; twins-atr@unimelb.edu.au 
Professor Stephen Simpson, Academic Director of the $\mathrm{CPC}$, introduced the event by highlighting the importance of the Twins Research Node as a greatly connected research hub at the Centre. He was followed by Professor John Hopper, Director of the ATR, who explained the role of the NHMRC's Centre of Research Excellence grant awarded to the registry to foster multidisciplinary collaboration across the research community and further empower twin research in Australia and globally.

The first scientific session was led by keynote speaker, Professor Jan Hartvigsen (University of Southern Denmark), who presented information on the current state of the Danish Twin Registry, including data linkage, biobanking, and new waves of data collection. He also showcased recent findings from his twin study of risk factors for low back pain, concluding that there appears to be a strong hereditary link to early back pain. Chronic back pain can start in children from the age of 10, and if not treated early can lead to lifelong problems. He was followed by Professor Hopper's presentation about 'The why and how of twin studies', in which twin designs and their range of different applications were explained. This session was rounded off by a presentation by Professor Perminder Sachdev (University of New South Wales), who highlighted research findings arising from the Older Australian Twins Study, a longitudinal study focused on the genetic contributions to neuropsychological factors and brain ageing.

The second scientific session started with Dr Justine Gatt (University of New South Wales), who presented research findings on twin studies aiming at understanding the genetics and neuroscience of resilience and wellbeing. Emeritus Professor Brian Byrne (University of New England) then demonstrated the value of twin studies in behavioral science and presented recent findings from his NAPLAN Reading and Numeracy study. He found, for example, that the influence of teachers on differences in reading ability within a school grade is much smaller than most people and the media might think, and explained that this was testimony to the high level of uniformity in the quality of teaching in Australian schools. Dr Paulo Ferreira (University of Sydney) explained how low back pain research is benefiting from the involvement of twins as study participants. He also showcased initial results from the new Brazilian Twin Registry, which he leads in collaboration with the ATR. Associate Professor Jeff Craig, Deputy Director of the ATR, discussed how twin research is making a major impact on the study of epigenetics and the developmental origins of health and disease.

Twins themselves played an important role in the launch of the Twin Research Node by participating in a panel discussion moderated by Professor Simpson. The twins discussed anecdotes and stories about their lives as twins, studies in which they have participated, and how their participation sparked their curiosity on how different twins from within a pair can be. This panel discussion showed the high level of engagement twins can have as research participants, proving to be a great resource for studies in medical, behavioral, socioeconomic, and many other research areas. In his closing remarks, Professor Hopper highlighted the importance of twins, researchers and twin registries in 'helping understand what it is to be human'. 'As a research community, we are very fortunate in Australia to have a resource such as the Australian Twin Registry and the twins who are members of the ATR, numbering some 35,000 twin pairs and their families, forming the largest voluntary twin registry in the world,' he concluded.

The event received a wide coverage from the media, including stories on numerous Australian television channels, such as Channel 7, Channel 9, ABC News, and Southern Cross Television, with an estimated total audience reach of more than 3 million people. The Twin Research Node launch event brought twins and researchers together to discuss the benefits of twin research. While the presentations covered a wide array of studies, research areas and topics, the main takeaway messages were that: (1) twins are special because they can help researchers better understand the roles of genes and environment on human traits and diseases, (2) twin studies are an important tool in a researchers' repertoire, and (3) twin studies provide insights that are relevant to the whole population.

\section{The Online Survey}

The objective of the online survey was to understand the CPC researchers' perceptions of their level of interest, understanding, and engagement with twin research for the educational purposes of the recently created Twins Research Node. Invitations were sent by email to all researchers at the CPC involved with at least one research node at the time, followed by a reminder sent one week later. There were 30 complete responses, obtained between October 20 and 28, 2015.

About $50 \%$ of the respondents were mid-career researchers, $13 \%$ were late-career researchers, $10 \%$ were Masters or PhD students, and 27\% marked 'other'. Most of the surveyed researchers were involved with nutrition as a research theme $(47 \%)$, followed by physical activity (33\%), exercise and energy expenditure (10\%), Aboriginal and Torres Strait Islander health (10\%), complex systems and computer modeling $(10 \%)$ and politics, governance and ethics $(10 \%)$. Only four (13\%) declared no involvement with any of those themes, while other themes such as in vitro effects, obesity and eating disorders, and immunology were also cited in open text responses.

The surveyed sample was questioned about their level of understanding, interest, and applicability of twin research methodology to their research interests (Table 1). A majority had only a moderate-to-low understanding of twin research, which makes opportunities for training and knowledge exchange more relevant. A substantial 
TABLE 1

Level of Understanding, Interest, and Applicability of Twin Research

\begin{tabular}{|c|c|c|c|}
\hline Level & $\begin{array}{l}\text { Understanding of twin } \\
\text { research methodology }\end{array}$ & $\begin{array}{l}\text { Interest in twin } \\
\text { research methodology }\end{array}$ & $\begin{array}{l}\text { Applicability of twin research } \\
\text { to researcher's topics }\end{array}$ \\
\hline Extremely high & $3 \%$ & $27 \%$ & $23 \%$ \\
\hline High & $17 \%$ & $20 \%$ & $34 \%$ \\
\hline Moderate & $47 \%$ & $40 \%$ & $27 \%$ \\
\hline Low & $23 \%$ & $10 \%$ & $13 \%$ \\
\hline None & $10 \%$ & $3 \%$ & $3 \%$ \\
\hline
\end{tabular}

TABLE 2

Value and Likeliness to Use Twin Research and Interest in New Opportunities

\begin{tabular}{llll}
\hline Level & $\begin{array}{l}\text { Value of } \\
\text { twin } \\
\text { research }\end{array}$ & $\begin{array}{l}\text { Likeliness to use } \\
\text { twin research in } \\
\text { the future }\end{array}$ & $\begin{array}{l}\text { Interest in learning } \\
\text { about opportunities } \\
\text { with the TRN }\end{array}$ \\
\hline Extremely high & $34 \%$ & $23 \%$ & $27 \%$ \\
High & $40 \%$ & $10 \%$ & $30 \%$ \\
Moderate & $23 \%$ & $23 \%$ & $30 \%$ \\
Low & $3 \%$ & $30 \%$ & $10 \%$ \\
None & $0 \%$ & $14 \%$ & $3 \%$ \\
\hline
\end{tabular}

TABLE 3

Barriers to Using Twin Research

\begin{tabular}{lrl}
\hline Barriers to using twin research & Yes & No \\
\hline Twin research is not applicable to my research area & $13 \%$ & $87 \%$ \\
Twin research is too complicated & $7 \%$ & $93 \%$ \\
I don't have the skills to conduct a twin study & $17 \%$ & $83 \%$ \\
There is insufficient access to twins & $30 \%$ & $70 \%$ \\
Twin samples are not representative of the population & $7 \%$ & $93 \%$ \\
Twin research methodology is outdated & $7 \%$ & $93 \%$ \\
\hline
\end{tabular}

percentage of respondents (27\%) declared an extremely high level of interest in the twin research methodology, while most of the surveyed researchers (33\%) thought the level of applicability of twin research to their topics was high. Researchers were also asked whether they have ever involved twins in their research, and only $10 \%$ of them responded positively. This, together with the reported levels of understanding, interest and applicability, showcases a significant potential for growth in the twin research workforce, especially aimed at early- and mid-career researchers.

Respondents were asked about their perceptions of the value of twin research, their likeliness to use twin research in the future, and their interest in learning more about opportunities within the Twins Research Node (Table 2). While $73 \%$ reported a high or extremely high value of twin research, and a majority declared a moderate-to-high interest in learning about new opportunities through the node, most declared the likeliness to use it in the future to be low. Table 3 addresses the issue of the barriers perceived by respondents with regards to the use of twin research.

The biggest barrier was an insufficient access to twins, which can indeed represent a hurdle especially when studying rare diseases. However, twin registries' memberships are growing fast, and new developments to create an Interna-

\section{TABLE 4}

Learning Methodologies

Would the following learning mode about twin research methodology be suitable to you?

Workshop

Seminar

As part of a research course

Online learning module

Discussion forum

\begin{tabular}{rl} 
Yes & No \\
\hline $37 \%$ & $63 \%$ \\
$70 \%$ & $30 \%$ \\
$3 \%$ & $97 \%$ \\
$40 \%$ & $60 \%$ \\
$7 \%$ & $93 \%$
\end{tabular}

tional Network of Twin Registries (Buchwald et al., 2014) are allowing for worldwide recruitment of twins for research studies, presenting larger and more diverse samples.

The second most-cited barrier was the lack of skills to conduct a twin study. Although only $17 \%$ of the sample identified this as a barrier, it creates an opportunity for the Twins Research Node to engage in an educational strategy to address these gaps. Finally, respondents were asked about their preferred method of training in the twin research methodology (Table 4). While the majority identified a seminar to be the most valuable training delivery mode, $40 \%$ cited an online learning module to be adequate. These results show that researchers are becoming increasingly open to novel approaches to teaching and learning.

\section{Conclusion}

The establishment of the Twins Research Node at the CPC coincides with the current era of extensive collaboration in twin research. The CPC's Twin Research Node will not only support the CPC in addressing relevant questions on the global burden of obesity, diabetes, cardiovascular disease, and related conditions in a multidisciplinary way, but it will also play a definite role in fostering the adoption of twin research into the researcher's toolbox for scientific discoveries not otherwise possible. There is a clear potential for developing an even stronger workforce of twin researchers so research projects can yield more compelling and significant findings.

\section{Acknowledgments}

We acknowledge Jenny and Sarah Colegrove, Maria Burgin and Helen Xinos, Phil and Stuart Daniel, Hugh and George Lloyd for participating in the launch event, and all the twins 


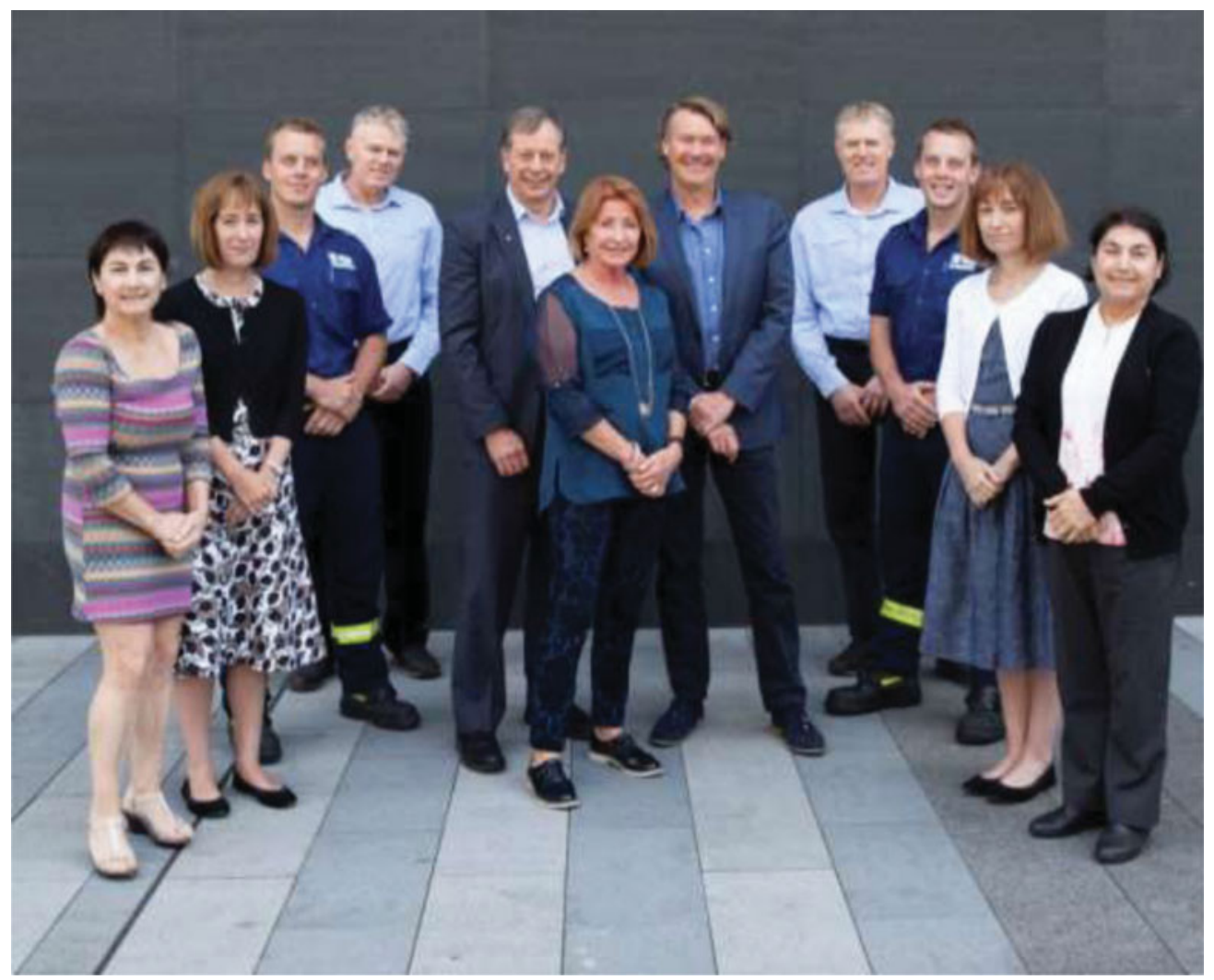

\section{FIGURE 1}

(Colour online) Twins and researchers.

and HOMs who have voluntarily enrolled with the ATR and contributed so much to the research it has supported.

\section{Financial Support}

This manuscript was facilitated by the ATR, a national resource supported by a Centre of Research Excellence Grant (1079102), from the National Health and Medical Research Council. This work was also supported by Coordenação de Aperfeiçoamento de Pessoal de Nível Superior (CAPES), Ministry of Education, Brazil (0903-14-0).

\section{References}

Buchwald, D., Kaprio, J., Hopper, J. L., Sung, J., Goldberg, J., Fortier, I., ... Harris, J. R. (2014). International network of twin registries (INTR): Building a platform for international collaboration. Twin Research and Human Genetics, $17,574-577$.

Segal, N. L. (2015). News, views and comments. Twin Research And Human Genetics, 18, 218-224. 